\title{
Educación musical en la escuela brasileña: aspectos históricos, legislación educacional y desafios contemporáneos
}

\author{
Music Education in the Brazilian School System: Historical \\ Aspects, Educational Legislation and Current Challenges
}

\author{
por \\ Sérgio Figueiredo \\ UDESC - Brasil \\ sergiofigueiredo.udesc@gmail.com
}

\begin{abstract}
Este texto aborda cuestiones generales sobre la educación musical brasileña enfocadas a la escuela de enseñanza regular. Los principales objetivos son el tratar sintéticamente aspectos históricos referentes a la presencia de la música en la escuela brasileña asociados a la discusión de elementos de la legislación educacional que han normado las cuestiones de educación musical en diferentes períodos. Además, pretende identificar los desafíos actuales de la educación musical en Brasil a partir de la aprobación de la ley específica que establece la obligatoriedad de la música en la escuela. Las orientaciones oficiales para la educación musical escolar en Brasil en distintos momentos históricos han sido formuladas a través de diversos documentos que serán brevemente destacados, de modo de establecer puntos para la discusión acerca de los desafíos contemporáneos de la educación musical para la escuela brasileña. La reflexión sobre la experiencia pasada y la superación de los desafíos inherentes a la implementación de la educación musical para todos en la escuela constituyen elementos fundamentales que deben ser considerados en las acciones para la aplicación de propuestas democráticas para la educación musical en la escuela brasileña.
\end{abstract}

Palabras clave: Educación musical, Escuela brasileña, Legislación educacional.

General topics about the Brazilian music education are discussed focusing upon the regular school system. The article briefly presents historical aspects regarding the presence of music teaching in the Brazilian school system. Besides federal laws related to the orientation of the music teaching process in different periods are discussed. The author seeks to identify current challenges facing the Brazilian music education system arising from the passing of a specific federal law that established music as a compulsory component of the school curriculum. Official orientations for music education in different historical periods of the Brazilian school system are briefly outlined on the basic of several documents, so as establish specific topics for the discussion of these current challenges. Reflection upon the experience of the past and overcoming the challenge of implementing music education for all in the school system are the fundamental elements that should be considered for the application of democratic proposals for music education in Brazilian schools.

Keywords music education, Brazilian school, educational legislation. 


\section{INTRODUCCIÓN}

La educación musical en Brasil puede ser estudiada a partir de distintas perspectivas. Una de ellas podría considerar aspectos de la historia de la educación musical brasileña con sus diversos períodos y propuestas, relevando acciones que establecen una mayor o menor evidencia sobre la función de la música en la formación escolar. Otra perspectiva podría referirse a la legislación educacional que norma la enseñanza de la música en la escuela en diversos períodos, cuyas consecuencias se hacen notar en diversas aproximaciones adoptadas por la escuela brasileña. Hay, aún, otra perspectiva que podría abordar los desafíos constantes de cualquier proceso educacional, ya que los cambios sociales afectan directamente a la escuela, al currículo y a los contenidos que son aplicados.

Este texto incluye las tres perspectivas enunciadas -historia, legislación y desafíos- considerando a todas relevantes y pertinentes para una comprensión del proceso educacional que involucra a la música en la escuela brasileña. Evidentemente, tales perspectivas no agotan las discusiones sobre el tema. En consecuencia, este texto debe considerarse como una síntesis posible que explora una parte de los aspectos referentes a la enseñanza musical en la escuela brasileña.

Cabe destacar que la investigación brasileña aún no incluye de una manera sistemática la indagación sobre la historia de la educación musical en sus diversas vertientes. Existen trabajos publicados que mencionan, citan y discuten aspectos de dicha historia y que contribuyen, en cierta forma, a la construcción de un cuerpo de conocimientos que todavía requiere una mayor sistematización. Este artículo revisa, a partir de la literatura existente, los aspectos históricos conectados a la legislación educacional brasileña referente a la música, una cuestión que es considerada relevante por los autores consultados, los que asumen la necesidad de una mayor profundización en cuestiones de investigación sobre este campo.

Es importante resaltar también que la educación musical no se hace sólo en la escuela. Puede darse igualmente en otros espacios tales como conservatorios, escuelas de música, iglesias y grupos folclóricos, entre otros. En este texto, sin embargo, trataremos la educación musical escolar por una cuestión de enfoque. No obstante, se reconoce la existencia de esos otros ámbitos, los que se basan en normativas y reglamentos distintos. Este escrito, reiteramos, discute aspectos de la educación musical formal realizada en la escuela de educación general en Brasil.

\section{ASPECTOS HISTÓRICOS DE LA EDUCACIÓN MUSICAL BRASILEÑA}

La música está presente en la educación brasileña a partir de la acción de los jesuitas, que pueden ser considerados como "pioneros educacionales" en el período comprendido entre 1549 y $1759^{1}$. Los jesuitas enfatizaron la práctica musical como una forma de establecer la religión católica sobre la base de prácticas musicales que seguían rigurosamente los preceptos de la música europea. La es-

\footnotetext{
${ }^{1}$ Olivera 2007. Los jesuitas fueron expulsados de los territorios portugueses en 1759, ocho años antes que lo hiciera la corona española de los suyos (N. del E.).
} 
cuela brasileña de este período era una institución en construcción, con un proceso educativo en el que participaba una parte reducida de la población ${ }^{2}$.

Los primeros documentos oficiales que evidencian la presencia de la enseñanza de música en la escuela brasileña datan del siglo XIX. El decreto 1331 del año $1854^{3}$, por ejemplo, establece que las nociones de música junto a ejercicios de canto deberían ser enseñados en las escuelas primaria y secundaria. En 1890, el decreto $981^{4}$ señala la necesidad de una "preparación específica para profesores de música" 5 .

Entre las décadas de 1930 y $1950^{6}$ el canto orfeónico ideado y organizado por Heitor Villa-Lobos (1887-1959) constituye una referencia en términos de la educación musical para la escuela brasileña. Esta experiencia, que sistematizó la enseñanza de la música en las escuelas, fue implementada a través del decreto 19.890 de 19 de abril de $1931^{7}$. Tal decreto trataba de cuestiones de la enseñanza secundaria en Brasil, y la música (en tanto canto orfeónico) estaba incluida en las tres primeras series del entonces denominado Curso Fundamental, que era parte integrante de la enseñanza secundaria. Para la implementación del proyecto de canto orfeónico fue creado el SEMA (Superintendencia de Educación Musical y Artística, posteriormente denominada Servicio de Educación Musical y Artística), organismo responsable por la formación de profesores y la producción de material didáctico para ser usado en las escuelas. Los objetivos principales del canto orfeónico eran "civismo, disciplina y educación artística"8, y estaban alineados con el modelo político del gobierno del presidente Getúlio Vargas (1882-1954). La presencia de la música en la escuela era concebida como un instrumento capaz de eliminar las diferencias sociales", exaltando el sentido de "colectividad, patriotismo y disciplina" 10 . En esta perspectiva, el folclore nacional, los himnos y las canciones patrióticas alcanzaron relevancia como repertorio esencial durante el período de canto orfeónico, en el que se buscaba desarrollar la noción de "identidad musical brasileña" a través del canto en grupo ${ }^{11}$.

A partir de la década de 1960 el canto orfeónico dejó de hacer parte de las actividades obligatorias de las escuelas brasileñas. Las "actividades complementarias de iniciación artística” fueron establecidas por la LDB $4024^{12}$. En este período se incorporaron, aunque de manera irregular y asistemática, las ideas de estudiosos de la educación musical de diferentes países europeos, tales como Dalcroze,

\footnotetext{
${ }^{2}$ Para ampliar este tema véase de Marcos Tadeu Holler, Uma história de Cantares de Sion na terra dos Brasis: a música na atuação dos Jesuitas na América Portuguesa (1549-1759), tesis de Doctorado en Música del Instituto de Artes da UNICAMP, Campinas, Brasil, 2006 (N. del E.).

${ }^{3}$ Brasil 1854.

${ }^{4}$ Brasil 1890 .

${ }^{5}$ Fonterrada 2005: 194.

${ }^{6}$ Figueiredo 2009a.

${ }^{7}$ Brasil 1931.

${ }^{8}$ Fucks 2007: 19.

${ }^{9}$ Souza 2007.

${ }^{10}$ Hentschke y Oliveira 2000: 47.

${ }^{11}$ Fonterrada 2005: 197.

${ }^{12}$ Brasil 1961.
} 
Orff y Kódaly, así como también las propuestas desarrolladas en Brasil por el movimiento de iniciación musical que se desarrollara paralelamente al de VillaLobos. Sin embargo, ni las ideas de los autores europeos, ni las propuestas del movimiento de iniciación musical alcanzaron a la totalidad de las escuelas. Tampoco llegaron a constituirse en un modelo de educación musical que se aplicara en todo el territorio nacional. Cabe destacar que este período -década de 1960también estuvo marcado por orientaciones educacionales que enfatizaban el tecnicismo y la relación inmediata entre educación y trabajo. En este contexto las artes en general y la música en particular fueron desplazadas gradualmente a un plano inferior en la formación escolar. Consecuentemente, esto provocó la desvalorización de este tipo de contenidos en la escuela.

A partir de la década de 1970 , con la aprobación de la ley $5692^{13}$, fue creada la "educación artística", una actividad curricular que incluía las artes escénicas y visuales, el diseño geométrico y la música. La idea de integración entre los lenguajes artísticos fue transformada en un modelo denominado "polivalencia", que concebía la formación de un profesor capaz de dar cuenta de todos los lenguajes artísticos. Para la concreción de esta práctica de polivalencia fueron creados los cursos superiores de educación artística (licenciatura) que formaban al profesor en dos etapas. La primera de ellas, denominada licenciatura corta con dos años de duración, preparaba al profesor polivalente de educación artística para desempeñarse en los primeros años del $1^{\mathrm{er}}$ grado, para estudiantes de entre 7 y 10 años. La segunda etapa, denominada licenciatura plena, preparaba al profesor en una de las áreas específicas de las artes para desempeñarse en los años finales del $1^{\mathrm{er}}$ grado, para estudiantes de 10 a 14 años y también en el $2^{\circ}$ grado, para estudiantes de 15 a 17 años. En la práctica, la escuela prefería al profesor polivalente capaz de lidiar con todas las áreas artísticas. En muchos casos, el profesor especializado en un solo lenguaje artístico jamás fue requerido. La experiencia de la educación artística en la educación brasileña dejó huellas profundas, desgraciadamente negativas, en relación al papel y a la relevancia de la enseñanza de las artes en la formación escolar. Aún hasta hoy se lucha en Brasil para que la enseñanza de las artes se considere e incorpore seriamente a la escuela regular, así como para que sus contenidos sean impartidos de manera consistente por profesionales habilitados en las áreas específicas.

En términos legales, la experiencia de la educación artística polivalente duró de 1971 a 1996. En este último año fue aprobada una nueva ley en cuyo texto se encuentra una mención específica para las artes. El texto dice: "La enseñanza del arte constituirá un componente curricular obligatorio en los diversos niveles de la educación básica, a fin de promover el desarrollo cultural de los alumnos"14.

Esta nueva determinación legal sugiere un cambio de aquello que se venía practicando anteriormente, toda vez que no menciona ni a la educación artística

\footnotetext{
${ }^{13}$ Brasil 1971.

${ }^{14}$ Brasil 1996, art. 26, párrafo 2․ En el portugués original se lee: "O ensino da arte constituirá componente curricular obrigatório, nos diversos níveis da educação básica, de forma a promover o desenvolvimento cultural dos alunos".
} 
ni a la polivalencia. Asimismo, en su artículo $8^{\circ}$ se refiere al régimen colaborativo entre el gobierno, los estados, el Distrito Federal y los municipios que debe ser establecido por los respectivos sistemas de enseñanza ${ }^{15}$. En el segundo párrafo del mismo artículo se establece que "Los sistemas de enseñanza tendrán la libertad de organización dentro de los términos de esta ley”. Esta libertad de organización representa un avance en el contexto brasileño si se considera la diversidad cultural existente en un país de proporciones continentales. En otras palabras, cada sistema educacional en las distintas regiones puede y debe respetar las particularidades correspondientes a sus propios universos sociales, económicos, políticos y culturales. No obstante, al mismo tiempo, la libertad de organización permite que los sistemas educacionales mantengan la práctica de polivalencia para la enseñanza de las artes. Son escasos los sistemas educacionales que contratan profesores especializados para cada lenguaje artístico. Las razones económicas de tal práctica son bastante obvias. Además, existe una concepción fuertemente arraigada en la comunidad educacional de que las artes, y consecuentemente la música, es un área menos relevante que otras para la formación de los estudiantes, o que el conjunto de los contenidos curriculares artísticos constituye un universo indisociable.

Cabe destacar que la propia ley 9394 de 1996 señala la obligatoriedad de una base nacional común y otra parte diversificada para los currículos escolares. En otras palabras, la libertad garantizada por la ley implica también determinaciones que todos los sistemas educacionales deben cumplir. Esto se aplica también al área artística cuya enseñanza es obligatoria en la escuela brasileña. Pero ¿qué arte es este?, ¿qué contenidos incluye?, ¿quién lo va a enseñar? son preguntas que deben ser respondidas por cada sistema educacional, respetando las orientaciones generales de la legislación nacional.

$\mathrm{Al}$ respecto, los documentos titulados Parámetros Curriculares Nacionales o $\mathrm{PCN}^{16}$ merecen un comentario. Estos documentos, producidos y divulgados por el Ministerio de Educación, presentan orientaciones generales sobre cada disciplina del currículo escolar para la enseñanza fundamental, para estudiantes de 7 a 14 años. No obstante, al no constituir parte de la legislación no son de cumplimiento obligatorio. Sin embargo, entre tales documentos se incluye un volumen específico denominado Arte, que da cuenta de las artes visuales, la danza, la música y el teatro como áreas que pueden ser impartidas en la escuela. Por cuanto estos documentos no tienen un carácter obligatorio, sus contenidos pueden ser incorporados o no por los sistemas educacionales. De hecho, esto no contribuye a la presencia sistemática de la enseñanza artística en la escuela. En esta perspectiva, muchos sistemas educacionales han preferido implementar una experiencia polivalente. El área de música, por ejemplo, ha estado ausente de las propuestas de varias escuelas, muchas de las cuales están vinculadas a actividades superficia-

\footnotetext{
${ }^{15}$ Se entiende por sistemas de enseñanza (o sistemas de educación) a un conjunto de escuelas con una administración común, de tipo estatal o privado. Por ejemplo, en Brasil cada estado y cada municipio tienen su sistema educacional constituido por una red de establecimientos escolares.

${ }^{16}$ Brasil 1997, 1998.
} 
les y poco relevantes en el contexto escolar, tales como animar ${ }^{17}$ las fiestas escolares, entre otras.

La investigación en educación musical brasileña ha evidenciado que existe una predominancia de las artes visuales en las clases de arte en las escuelas ${ }^{18}$. Además, la propuesta polivalente para la enseñanza de las artes es todavía muy solicitada y practicada. Esto significa, de un modo general, que el profesor administra algunos contenidos de diferentes lenguajes artísticos pero sin mayor profundización, ya sea por las limitaciones del tiempo destinado a las clases o por su falta de competencia específica. La práctica de la polivalencia en la escuela reproduce y perpetúa hasta el día de hoy una propuesta artística de la década de los setenta, junto con ignorar toda la discusión acumulada sobre la fragilidad e inconsistencia de aquel modelo. En el área de la música los debates en torno a la cuestión de la polivalencia de la enseñanza de las artes en la escuela ${ }^{19}$ son variados. Lo que es común en el discurso de varios autores es exactamente la imposibilidad de formar adecuadamente un profesor, capaz de lidiar con todos los lenguajes artísticos en la escuela en un corto plazo de tiempo, normalmente cuatro años. La insuficiente formación de este profesional promueve una educación musical inconsistente e irrelevante. Produce, muchas veces, resultados negativos en relación a la importancia de la música para el ser humano junto con perpetuar la noción de talento, que considera que algunos seres humanos son dotados de talentos especiales y que solamente estos individuos serían capaces de aprender música $^{20}$.

Por otra parte, persiste una fuerte concepción de que la música se enseña para ser músico, lo que no ocurre con otras disciplinas escolares. En tal sentido, no se enseña matemática para formar matemáticos, ni ciencias para formar científicos. Dentro de esta misma lógica, la música podría ser incorporada a la formación de los individuos sin la pretensión de formar músicos necesariamente. No obstante, modificar tales creencias, tanto en la sociedad en general como en la comunidad educacional en particular, es un lento y paulatino proceso de cambio de mentalidad.

A partir de la vigencia de la ley anteriormente mencionada ${ }^{21}$, se han producido diversos debates referidos especialmente a la interpretación de su texto, el cual establece la enseñanza del arte pero no ofrece mayores definiciones sobre qué lenguajes artísticos deberían ser parte de ella ${ }^{22}$. Lo que se constata en la práctica es que muchos sistemas educacionales mantienen la misma propuesta del modelo anterior -educación artística polivalente- considerando que el texto de la ley solo modificó la nomenclatura de las disciplinas, pero no su concepción, formato ni contenidos. El mismo texto de ley prescribe la obligatoriedad de la

\footnotetext{
${ }^{17}$ En el original "enfeitar", literalmente "adornar" (N. del E.)

${ }^{18}$ Penna 2002.

${ }^{19}$ Tacuchian 1992; Hentshcke 1993; Tourinho 1993; Oliveira 1999, 2000a, 2000b; Figueiredo 2000, 2003.

${ }^{20}$ Schmidt 2005, 2006, 2008.

${ }^{21}$ Brasil 1996.

${ }^{22}$ Figueiredo 2003.
} 
enseñanza del arte en los diversos niveles de la educación básica. Esta comprende desde la educación infantil, para estudiantes hasta los 5 años, la enseñanza fundamental, para estudiantes de 6 a 14 años, hasta llegar a la enseñanza media, para estudiantes de 15 a 17 años. No obstante, la disposición legal no aclara en cuántos años debería estar presente la enseñanza artística, con cuántas horas semanales, qué tipo de profesor debería ser responsable por la enseñanza de esta(s) área(s), qué contenidos deberían impartirse y así por el estilo.

Todas estas cuestiones han sido respondidas por los propios sistemas educacionales, los que, en virtud de su autonomía, deben organizar el conjunto de aspectos que comprenden la educación en distintos contextos ${ }^{23}$. Esto quiere decir que desde 1996, año en que se aprueba la ley 9394, los sistemas educacionales tienen autonomía para decidir cómo enseñar las artes en la escuela, cuántas horas se dedicarán a estas áreas, en qué secuencia y qué tipo de profesional debe ser responsable de ella. Sin embargo, en la mayoría de los sistemas educacionales que han preferido mantener la idea del arte como una actividad única impartida por un solo profesional, tal autonomía no ha sido ejercida.

En algunos sistemas educacionales la práctica polivalente fue eliminada y se contratan profesores específicos. Esto puede significar que una escuela que tenga un único profesor de arte, especializado en artes visuales, a modo de ejemplo, va a trabajar solamente en esta área curricular. Por lo tanto, los alumnos de esa escuela no tendrían formación en otras áreas artísticas debido a la carencia de profesionales habilitados para ello. Tal situación, que no es ideal por cuanto se espera de la escuela una formación amplia, al menos no adopta la polivalencia. De este modo se admite que un profesor habilitado en un área no debería ejercer en $\operatorname{otras}^{24}$.

Con el propósito de mejorar la legislación vigente y asegurar la presencia de la música en la escuela -que, como se ha señalado, está potencialmente garantizada por medio de la enseñanza artística obligatoria del cuerpo legal de $1996^{25}$

\footnotetext{
${ }^{23}$ La escuela brasileña ofrece actividades para los diversos niveles normalmente en períodos de aproximadamente 4 horas de duración (matutino, vespertino y nocturno), de modo que los estudiantes pasen una parte del día en la escuela. Esto asciende a unas 20 horas de clases semanales que incluyen las disciplinas referentes a los diversos niveles escolares. Este número puede variar en algunos niveles al ser ampliado en un determinado número de horas ofrecidas en el período de clases opuesto al regular. A modo de ejemplo, una clase de educación física puede ser por la mañana si los estudiantes asisten regularmente por la tarde, y viceversa. La cantidad de clases de cada asignatura es establecida por cada sistema educacional y puede variar significativamente en diversas partes del país. Las clases de arte están incluidas en este conjunto de asignaturas y presentan diversos formatos y cantidad de clases. Existen sistemas educacionales, por ejemplo, que ofrecen una clase de arte a la semana, otros dos y aún tres, siendo impartidas de manera polivalente (un profesor para todas las artes) o específica (un profesor para cada disciplina). La libertad de los sistemas educacionales permite estas y otras muchas variantes. Sin embargo, algunas experiencias de "escuela de tiempo completo" amplían la jornada escolar a todo el día, lo que significa un aumento horario que puede aplicarse a cada asignatura. Aunque estas experiencias son recientes ya se tiene noticia que las clases de artes han sido ampliadas en esa modalidad. En resumen, la enseñanza de las artes, en conjunto o separadamente, es aún extremadamente diversa en todo Brasil.

${ }^{24}$ Figueiredo 2000.

${ }^{25}$ Penna 2002, 2004.
} 
surgió un movimiento nacional que aglutinó a instituciones y profesionales del área de la música en general. Este movimiento, coordinado por el Grupo de Articulación Parlamentaria Pro Música (GAP) y contando con la decidida participación de la Asociación Brasileña de Educación Musical (ABEM), fueron los protagonistas de la aprobación de la ley 11.769 del 18 de agosto de 2008 que se refiere a la obligatoriedad de la música a nivel escolar ${ }^{26}$. Esta nueva ley cambia la de 1996 en su artículo 26 junto con complementar aquello que está en vigor sobre la enseñanza del arte, pero precisando que la enseñanza de la música también hace parte del currículo. "La música deberá ser contenido obligatorio, pero no exclusivo, del componente curricular de que trata el párrafo $2^{\circ}$ de este artículo" 27 . Es este párrafo el que indica específicamente la obligatoriedad de la enseñanza del arte en la educación básica, ya mencionado ${ }^{28}$.

El proceso de discusión, elaboración y aprobación de esta reciente ley evidenció la posibilidad de un mejoramiento de las cuestiones educacionales brasileñas a partir de un enfoque específico en la educación musical. Todo el proceso estuvo marcado por la acción colectiva, e incluyó diversos puntos de vista en busca de una solución para la enseñanza de la música en la escuela que ha sido relatado en la literatura pertinente ${ }^{29}$. La nueva legislación favorece la enseñanza de la música en la escuela brasileña, pero esto no significa que todos los problemas estén resueltos. En la siguiente sección de este texto serán presentados los principales desafíos para la implementación de esta nueva legislación.

\section{DESAFÍOS PARA LA EDUCACIÓN MUSICAL BRASILEÑA CONTEMPORÁNEA}

Los diferentes períodos de la historia de la educación musical brasileña, con sus particularidades y perspectivas, posibilitan una serie de reflexiones que pueden ser importantes para el futuro de esta área en el currículo escolar de las diversas regiones del país. Los aspectos históricos de la educación musical brasileña, así como los elementos de la legislación educacional que regulan su enseñanza, los que acabamos de exponer, representan una breve síntesis que sirve de base para la siguiente discusión.

Al revisar la enseñanza de la música en la escuela del siglo XIX constatamos una limitada cobertura poblacional. Quienes frecuentaban la escuela en aquel período eran parte de un grupo selecto que representaba una pequeña porción de la población brasileña. Esto corrobora en cierta forma que la música estaba inserta en un contexto exclusivo, elitista e inaccesible para todos los ciudadanos en edad escolar. La elitización por falta de acceso a la educación musical, a modo de ejemplo, promueve y acentúa la idea de que no todos los individuos son aptos para aprender. Felizmente, esta concepción ha sido revisada a lo largo del tiempo y hoy en día el principio de inclusión, como gran política pública, ha contribuido a revisar los valores y creencias sobre la enseñanza musical.

\footnotetext{
${ }^{26}$ Brasil 2008.

${ }^{27}$ Brasil 2008, párrafo $6^{\circ}$.

${ }^{28}$ Brasil 1996, artículo 26, párrafo $2^{\circ}$.

${ }^{29}$ Figueiredo 2008a, 2008b, 2009a; Oliveira 2007.
} 
Otro aspecto que conviene destacar es la cuestión del canto colectivo que tiene su expresión máxima dentro de la educación musical brasileña en el canto orfeónico y la figura de Heitor Villa-Lobos ${ }^{30}$. La ideología política que respaldó la creación, implantación y mantención de este proyecto por casi tres décadas debe ser considerada, pero no constituye un impedimento para la utilización del canto en el proceso educacional en música. Para algunos más radicales, el hecho de que el canto orfeónico de Villa-Lobos estuviera vinculado a un modelo político autoritario es suficiente para considerar el canto coral como una actividad impropia para la educación musical contemporánea. Esto, desde nuestro punto de vista, constituye un gran error. No se trata de trasponer mecánicamente la experiencia del pasado a nuestros días, pero sí de valorar los elementos que pueden ser empleados actualmente, en el contexto de diferentes experiencias, contenidos y prácticas. El canto colectivo efectivamente puede favorecer la realización de experiencias significativas de enseñanza y aprendizaje musical, al explorar sonoridades y repertorios que dan cuenta de la diversidad cultural de nuestro tiempo. De igual manera, los problemas derivados de la práctica de la polivalencia en el período de educación artística, entre 1971 y 1996, deben ser conocidos para que se eviten las prácticas que produjeron tales problemas. No obstante, esto no significa que no sea posible trabajar integradamente con los diversos lenguajes artísticos, toda vez que se disponga de profesionales competentes para ello.

La legislación por sí misma no produce cambios y esto debe ser definitivamente asumido en las definiciones de políticas públicas para el área de la educación musical que se han impulsado a partir de la aprobación de la ley 11.769 de 2008. La obligatoriedad de la música ha sido vista de diversas maneras. El texto de la ley ha sido interpretado de diferentes formas, algunas de las cuales cuestionan la validez de este cambio legal conquistado gracias a la movilización nacional que surgió con la finalidad de alterar la legislación. Uno de los puntos fuertemente cuestionados es la afirmación en el texto de la ley de que la música "es un contenido obligatorio", lo que puede significar que ella no sería una disciplina específica en el currículo. Tal lectura tiene obvias referencias al modelo polivalente -un profesor que enseña todos los lenguajes artísticos- y la inclusión de la música en el currículo podría significar sólo la inclusión de algunos elementos dispersos presentes en cualquier disciplina del currículo.

El movimiento por la música en la escuela preveía que tal actividad sería asumida por profesionales habilitados para ello, lo que puede parecer extremadamente obvio. Mientras tanto, el artículo que trataba de esta formación específica fue vetado provocando insatisfacción de parte de muchos profesionales. La ley

\footnotetext{
${ }^{30}$ Algunos aportes recientes sobre este tema son los de Renato de Sousa Porto Giglioli, 'Civilizando' pela música: a pedagogia do canto orfeónico na escola paulista da Primeira República (1910-1930), Dissertação Mestrado em Educação, Faculdade de Educação da Universidade de São Paulo, São Paulo, 2003; Alessandra Coutinho Lisboa, Villa-Lobos e o Canto Orfeônico: música, nacionalismo e ideal civilizador, Dissertação Mestrado em Música, Instituto de Artes da Universidade Estadual Paulista Julio de Mesquita Filho, São Paulo, 2005; Rita de Cássia Fucci Amato, "Momento brasileiro: reflexões sobre o Nacionalismo, a educaçao musical e o Canto Orfeônico em Villa-Lobos”, Revista Electrónica Complutense de Investigación en Educación Musical, Madrid, V/2 (2008), disponible en el sitio web http: //www.ucm.es/info/reciem/index.htm.
} 
9394 de 1996, aun vigente, determina que sólo podrá ser profesor de educación básica aquel que tenga un diploma de estudios superiores de licenciatura ${ }^{31}$. Sin embargo, debido en parte a la jerarquización de las áreas del currículo, cualquier persona que tenga habilidades musicales ha sido, en diferentes contextos, considerada como apta para el ejercicio del magisterio en el área de la música.

En otras palabras, pareciera que para enseñar música no es necesario poseer conocimientos referentes a la didáctica específica de esta área, lo que no ocurre necesariamente con otras áreas del conocimiento. Se espera que el profesor de matemáticas tenga formación específica en tal área, o que el profesor de historia también esté formado en su especialidad. Pero con las áreas artísticas ocurre que cualquier experiencia al respecto es suficiente para habilitar a alguien como profesor de música. Esta situación ha generado discusiones que pueden ser estimulantes para los educadores musicales brasileños. Sobreira discute la situación de la formación del profesor considerando que la nueva ley no defiende la exclusividad del profesor de música para su desempeño en la escuela ${ }^{32}$. Lo que Sobreira no toma en cuenta en esta discusión es que para las otras áreas del conocimiento la legislación tampoco establece exclusividad. Lo que se precisa en este momento es un trabajo de toma de conciencia de parte de la comunidad escolar, inicialmente, y de la sociedad toda, gradualmente, para que la música sea comprendida en su importancia y relevancia en el proceso de formación educacional, conquistando espacio, legitimidad y estatus que garanticen la presencia de profesionales adecuadamente preparados para desempeñarse como profesores de música. Una vez más se necesita tiempo para que los cambios en este sentido ocurran, con acciones continuas y eficientes para promover los cambios deseados.

La exigencia de formación de nivel universitario para el desempeño como profesional de la educación básica ${ }^{33}$ puede ser una referencia para la mejora de la educación brasileña. Además de esta obligatoriedad de cursos superiores, el Ministerio de Educación ha trabajado continuamente en la definición y la revisión de directrices curriculares nacionales para todos los cursos universitarios. En esta política de revisión de los textos orientadores de las áreas del conocimiento, el propio Ministerio de Educación no reconoce más los estudios de educación artística, orientados a la formación de un profesional para desempeñarse indistintamente en cualquiera de los diferentes lenguajes artísticos. En la actualidad, este ministerio reconoce los estudios de formación específica para cada uno de los lenguajes artísticos, y se encuentran vigentes las Directrices Curriculares Nacionales para las áreas de música, de danza, de teatro y de artes visuales ${ }^{34}$. Tales directrices, sumadas a toda la discusión acumulada en las áreas de las artes, esta-

\footnotetext{
${ }^{31}$ Brasil 1996, artículo 62.

${ }^{32}$ Sobreira 2008.

${ }^{33} \mathrm{E}$ t término "educación básica" se refiere aquí al nivel escolar, en general, y no a la primera etapa de ella tal como lo entiende el sistema educacional chileno. Este sistema distingue hasta ahora cuatro niveles. Ellos son el nivel preescolar, el nivel básico, el nivel medio y el nivel universitario. Constituyen la escolaridad propiamente tal, los niveles básico y medio.

${ }^{34}$ Las fuentes son, respectivamente, las siguientes: Brasil 2004a (música); Brasil 2004b (danza); Brasil 2004c (teatro) y Brasil 2009 (artes visuales).
} 
blecen tácitamente el fin de la polivalencia en la enseñanza artística. Esto no quiere decir, evidentemente, que no se deba trabajar para la integración de contenidos de forma interdisciplinaria. No obstante, es fundamental la presencia de profesionales capacitados en cada área para la realización de esta tarea. Evidentemente los profesionales formados en los antiguos cursos de educación artística aún permanecen trabajando en las escuelas, y muchos de ellos actúan en forma polivalente. Comprendemos que este es un momento de transición de la enseñanza musical en la escuela brasileña a partir de la nueva legislación, lo que significa que diversas soluciones transitorias deberán ser encontradas por los sistemas educacionales. Estos, junto con aprovechar la experiencia anterior deberán establecer metas y plazos para que la música sea efectivamente incluida en la escuela en forma satisfactoria.

La formación de profesores de música es un aspecto fundamental para ocupar el espacio de la educación musical en la escuela. Diversos programas ministeriales han estimulado la ampliación de la oferta de vacantes, así como la creación de nuevos cursos para la formación de profesores y algunas de estas acciones también incluyen la formación de profesores de música. Al respecto, es preciso definir con mayor claridad esta política a fin de que más personas puedan incorporarse a este proceso. Junto a la necesidad de más profesores de música, otro de los grandes desafíos para la educación musical brasileña, es que los sistemas educacionales puedan estimular mejor a los profesores a fin de que se sientan motivados a ocupar el espacio escolar. Bajos salarios, malas condiciones de trabajo, cursos sobrepoblados, desvalorización de la música y las artes en las escuelas, son algunos de los aspectos que han desmotivado la presencia de más profesores de música en el espacio escolar.

Todo esto implica profundos cambios de mentalidad que toman tiempo para que ocurran. Desde 1971 la enseñanza de la música fue comprometida como una práctica de la educación artística. Sin embargo, en muchos casos estuvo ausente de la formación escolar. Esto significa que varias generaciones han sido privadas de vivencias musicales significativas en la escuela. Las personas que no vivieron tales experiencias, evidentemente tienden a considerar que la música no es tan relevante en la educación escolar y no apoyan necesariamente su inclusión en ella. Dentro de estas personas también están aquellas que hacen parte de la administración escolar y que toman decisiones sobre la escuela y su currículo. Por esta razón, todavía se encuentra resistencia para la inclusión de la música en el currículo escolar, ya que para una mayoría de profesionales del área la educación musical no ha representado un aspecto relevante en la formación escolar.

Toda mudanza toma tiempo y no resulta fácil que ocurra. Del mismo modo, muchos sistemas educacionales mantienen las mismas concepciones y prácticas empleadas tradicionalmente, por más que ellas sean ampliamente criticadas y consideradas inadecuadas para el sistema escolar. Es preciso reconocer la necesidad de un cambio así como asumir la responsabilidad por que éste ocurra. Esta falta de conciencia y compromiso ha sido uno de los mayores obstáculos para un proceso de cambio, pues los profesionales de la educación muchas veces esperan las decisiones de las autoridades educacionales y se sustraen a una participación 
activa en los procesos de implementación de nuevas ideas sobre la formación escolar.

Vinculando con todos los elementos discutidos anteriormente está la cuestión del método y del repertorio que deberían emplearse en la educación musical brasileña. Por las razones expuestas, los defensores de las prácticas que se han señalado han desestimado las discusiones y reflexiones acerca de los procesos educativos en música. A modo de ejemplo, aunque sea importante cantar en la escuela, el modelo de canto orfeónico no puede ser transpuesto literalmente 60 años después, como si el proceso de enseñanza y aprendizaje pudiera prescindir en su aplicación del contexto histórico y social. Además, la enseñanza de un repertorio erudito europeo no es el único modelo existente, ni puede dar cuenta de la diversidad musical y cultural del mundo actual. Esto implica una ampliación de las vertientes musicales que se incluyan en la formación de los estudiantes. No se trata, por lo tanto, de encontrar una metodología única que sea adecuada a todos en cualquier tiempo y lugar. Se trata de estimular una enseñanza musical que sea amplia e inclusiva, que respete diversas formas de hacer música y que, fundamentalmente, desarrolle habilidades musicales significativas en los diferentes contextos en los que se aplique.

\section{CONSIDERACIONES FINALES}

Observando las diversas propuestas de educación musical a lo largo de la historia es posible constatar la diversidad de objetivos y enfoques en la enseñanza de música en las escuelas brasileñas. Hasta hoy día se discute en el país sobre la pertinencia de la música como componente curricular escolar. Con énfasis en la formación religiosa o cívica, en la formación profesional y aun en la educación artística en general, la educación musical se ha configurado de manera discontinua en el escenario educacional brasileño, tanto por la ausencia de esta actividad en distintos momentos, como por el redireccionamiento radical de las propuestas.

A partir del año 2008 una nueva legislación establece la música como contenido obligatorio en la escuela brasileña, lo que puede considerarse positivo. En tanto, para el establecimiento de una educación musical consistente y democrática aplicada en todo el territorio brasileño, diversas acciones a corto, mediano y largo plazo deberán ser emprendidas por diferentes sectores de la sociedad.

Los sistemas educacionales deberán adaptarse a la nueva ley. No obstante, la lectura del texto legal puede ser hecha de varias maneras, en cuanto a incluir la música de forma sistemática y con calidad, o de manera periférica y eventual. Por lo tanto, no basta con la legislación, sino que es preciso trabajar con la cuestión de las concepciones sobre la música y su presencia en el currículo escolar. ¿Para qué sirve la música?, ¿por qué vamos a enseñarla en la escuela?, ¿es la música para todos?, ¿cuáles son los métodos más adecuados para su aplicación?, ¿qué repertorio debe incluirse en el currículo escolar brasileño?, son algunas de las preguntas que se han hecho a partir de la nueva legislación y que deberán ser respondidas oportunamente de acuerdo con las acciones desarrolladas en cada caso. 
Las universidades participan de este proceso ya que son responsables por la formación de los profesores que actuarán en la educación escolar. Los cursos universitarios deben mantenerse cercanos a los sistemas educacionales, interactuando, dialogando y construyendo asociadamente propuestas que posibiliten una educación musical de calidad. Además de la formación inicial, no se puede ignorar la necesidad de formación continua para profesores y otros profesionales de la educación, lo que también implica una acción conjunta con las universidades que pueden ser socias en este proceso de educación continua.

La comunidad escolar también deberá adaptarse a esta nueva legislación. Para algunos, el impacto inicial no fue positivo pues consideran que la música no debe ser obligatoria y que existen otras disciplinas más importantes en cuanto a ser enfatizadas en el currículo. Para otros, la presencia de la música en el currículo es una posibilidad de ampliar las acciones para la humanización de la escuela, ofreciendo experiencias significativas que desarrollen al ser humano en su totalidad. La participación de la comunidad en la escuela, discutiendo y construyendo conjuntamente la educación escolar, aportará un mayor sentido a todo el desarrollo de la formación del estudiante. La música también deberá ser discutida por la comunidad, procurando comprender su importancia, posibilidades, metodologías de enseñanza, repertorio y muchos otros aspectos relacionados con esta práctica humana.

Por más que esta sea una nueva fase en la educación musical brasileña, no se puede ignorar lo que se ha hecho, a pesar de todos los problemas señalados y discutidos sumariamente en este texto. Existen profesionales dedicados, preparados y con disposición para trabajar con la música, a pesar de muchas adversidades. La actual producción intelectual sobre educación musical ofrece referencias importantes para el desarrollo de propuestas consistentes y adecuadas para los diferentes contextos educacionales. La ABEM, Asociación Brasileña de Educación Musical, ha contribuido sistemáticamente a la ampliación del debate sobre diferentes aspectos de la educación musical y parte de esta producción puede ser encontrada en sus publicaciones on line (www.abemeducacaomusical.org.br).

Muchos serán los obstáculos que se deberán superar hasta que la educación musical brasileña esté accesible democráticamente para toda la población escolar y, consecuentemente, para que toda la sociedad disfrute en diferentes situaciones de las experiencias ofrecidas en la escuela. La experiencia con la banda o el coro escolar, por ejemplo, es fundamental para la ampliación de las referencias en la formación escolar, pero está restringida a una limitada cantidad de estudiantes. Solamente la música en el currículo garantizará que la experiencia musical haga parte de la formación de los individuos que pasan por la escuela, participando y accediendo activa, continua y autónomamente a los bienes culturales de la humanidad. Estos son los grandes desafíos para la educación musical brasileña contemporánea, desafíos que exigen un protagonismo permanente de los profesionales de la educación que deben participar, opinar y realizar propuestas adecuadas a la educación brasileña. Es preciso romper con la idea del profesor que solamente ejecuta las propuestas elaboradas por otros, a fin de que asuma la autoría competente de propuestas en los diversos contextos educacionales. La legislación es fa- 
vorable en este momento. No obstante, es fundamental que se establezca un compromiso con la educación brasileña que debe ser asumido colectivamente en favor de la formación de una sociedad más humana que pueda disfrutar de la experiencia musical en forma plena.

\section{BIBLIOGRAFÍA}

\section{Abreviaturas}

$\begin{array}{ll}\text { CNE/CES } & \text { Conselho Nacional de Educação/Câmara de Educação Superior } \\ \text { ISME } & \text { International Society of Music Education } \\ \text { RMIT } & \text { Royal Melbourne Institute of Technology } \\ \text { SEDUC } & \text { Secretaria de Educação } \\ \text { UFPR } & \text { Universidade Federal do Paraná } \\ \text { UFRGS } & \text { Universidade Federal do Rio Grande do Sul } \\ \text { UFSM } & \text { Universidade Federal de Santa Maria } \\ \text { UNB } & \text { Universidade de Brasília } \\ \text { UNESP } & \text { Universidade Estadual Paulista } \\ \text { UNICAMP } & \text { Universidade de Campinas } \\ \text { UNLAM } & \text { Universidad Nacional de La Matanza } \\ \text { USP } & \text { Universidade de São Paulo }\end{array}$

Figueiredo, SÉrgio

2000 "Documento referente à elaboração de currículos - Música", Subsídios para a reorganização didática no ensino fundamental. Florianópolis: Secretaria Municipal de Educação, pp. 233-249.

2003 The Music Preparation of Generalist Teachers in Brazil. Tesis de doctorado. Melbourne, Australia: RMIT University.

2008a "A participação da ABEM no processo da volta da educação musical para a escola", Anais do XI Encontro Regional Sul da ABEM (CD Rom). Santa Maria: UFSM/ABEM.

2008b "A ABEM e o projeto nacional de música na escola”, Anais do VIII Encontro Regional da ABEM Centro-Oeste, $1^{\circ}$ Simpósio sobre o Ensino e a Aprendizagem da Música Popular e III Encontro Nacional de Ensino Coletivo de Instrumento Musical (CD Rom). Brasilia: UNB/ABEM.

2009a "O ensino de música na educação brasileira: um breve panorama a partir da legislação educacional”, O ensino de música: desafios e possibilidades contemporâneas. Volumen I. Goiânia: SEDUC - Governo de Goiás, pp. 81-89.

2009b "Um breve panorama da educação musical no Brasil", VII Encuentro Regional Latinoamericano, ISME 2009 (CD Rom). Buenos Aires: UNLAM.

Figueiredo, Sérgio y Alda Oliveira

2007 "A Associação Brasileira de Educação Musical - ABEM: 15 Anos de História", Educação Musical no Brasil. Salvador, Bahía: P \& A, pp. 53-64.

Figueiredo, Sérgio y Luciana Schmidt

2005 "Discutindo o talento musical", Anais do 1. Simpósio Internacional de Cognição e Artes Musicais. Curitiba: UFPR, pp. 385-392.

2006 "Discutindo o talento musical a partir da visão de estudantes de música", Anais do 1. Encontro Nacional de Cognição e Artes Musicais. Curitiba: UFPR, pp. 209-214. 
2008 "Refletindo sobre o talento musical na perspectiva de sujeitos não-músicos", Anais do 4. Simpósio Internacional de Cognição e Artes Musicais (CD Rom). São Paulo: USP, Disponible en: http://www.fflch.usp.br/dl/simcam4/anais_simcam4.htm

FonterRada, Marisa

2005 De tramas e fios: Um ensaio sobre música e educação. São Paulo: Editora da UNESP.

Fuks, Rosa

2007 "A educação musical da Era Vargas: Seus precursores”, Educação Musical no Brasil. Alda Oliveira y Regina Cajazeira (organizadoras). Salvador: P\&A, pp. 18-23.

HentschKe, LiAne

1993 "Relações da prática com a teoria na educação musical", Anais do II Encontro Anual da ABEM. Porto Alegre: ABEM, pp. 49-67.

Hentschke, Liane e Alda Oliveira

1999 "Music Curriculum Development and Evaluation based on Swanwick's Theory", International Journal of Music Education, $\mathrm{N}^{\circ}$ 34, pp. 14-29.

2000 "A educação musical no Brasil”, Educação musical em países de línguas neolatinas. Liane Hentschke (editor). Porto Alegre: Editora da Universidade/UFRGS, pp. $47-64$

Oliveira, Alda

2000a "Street Kids in Brazil and the Concept of Teaching Structures", International Journal of Music Education, $\mathrm{N}^{\circ} 35$, pp. 29-34.

2000b "Currículos de música para o Brasil 2000", Anais do XIX Encontro Anual da ABEM (Belém). Porto Alegre: ABEM, pp. 5-17.

2007 “Aspectos históricos da educação musical no Brasil e na América do Sul”, Educação Musical no Brasil. Alda Oliveira y Regina Cajazeira (organizadoras). Salvador: P\& A, pp. 3-12.

Penna, Maura

2002 "Professores de música nas escolas públicas de ensino fundamental e médio: Uma ausência significativa", Revista da ABEM, N 7 (septiembre), pp. 7-19.

2004 "A dupla dimensão da política educacional e a música na escola: I- analisando a legislação e termos normativos”, Revista da ABEM, N 10 (marzo), pp. 19- 28.

Sobreira, SiLVIA

2008 "Reflexões sobre a obrigatoriedade da música nas escolas públicas", Revista da ABEM, Porto Alegre, $\mathrm{N}^{\circ} 20$ (septiembre), pp. 45-52.

SOUZA, JUSAMARA

2007 “A educação musical no Brasil dos anos 1930-45”, Educação Musical no Brasil. Alda Oliveira y Regina Cajazeira (organizadoras). Salvador: P\& A, pp. 13-17.

TACUCHIAN, RicARDO

1992 "Novos e velhos caminhos", Anais do I Encontro Anual da ABEM (Rio de Janeiro). Porto Alegre: ABEM, pp. 4-11.

Tourinho, Irene

1993 "Usos e funções da música na escola pública de $1^{\circ}$ grau", Fundamentos da Educação Musical, ABEM, v. 1, pp. 91-113. 


\section{Documentos}

BRASIL

1854 "Decreto n. 1.331 A, de 17 de fevereiro de 1854. Approva o regulamento para a reforma do ensino primário e secundário no Município da Côrte”. Coleção das Leis do Império do Brasil. Rio de Janeiro, tomo 17, parte 2ª , seção 12ª . Disponible en: http://www.histedbr.fae.unicamp.br/navegando/fontes_escritas/3_Imperio/ artigo_004.html

1890 Decreto n. 981, de 8 de novembro de 1890. Approva o regulamento da instrucção primaria e secundaria do Districto Federal. Rio de Janeiro. Disponible en: http:// www.histedbr.fae.unicamp.br/navegando/fontes_escritas/4_1a_Republica/decreto $\% 20981-1890 \%$ 20reforma\%20benjamin\%20constant.htm

1931 Decreto n. 19.890, de 18 de abril de 1931. Dispõe sobre a organização do ensino secundário. Rio de Janeiro. Disponible en: http://www.planalto.gov.br/ccivil_03/decreto/ 1930-1949/D19890.htm

1961 Lei de Diretrizes e Bases da Educação Nacional. Lei 4.024, de 20 de dezembro de 1961. Brasília. Disponible en: http://www.planalto.gov.br/ccivil_03/leis/4024.htm

1971 Lei de Diretrizes e Bases da Educação Nacional. Lei 5.692, de 11 de agosto de 1971. Brasília. Disponible en: http://www.planalto.gov.br/ccivil_03/leis/5692.htm

1996 Lei de Diretrizes e Bases da Educação Nacional, LDB: Lei 9394/96. Brasília: Diário Oficial da União, Ano CXXXIV, n. 248, de 23/12/96, pp. 27.833-27.841.

1997 Parâmetros Curriculares Nacionais (Introdução). Brasília: Ministério da Educação/ Secretaria de Educação Fundamental.

1998 Parâmetros Curriculares Nacionais $\left(5^{\underline{a}} a 8^{\underline{a}}\right)$. Brasília: Ministério da Educação/Secretaria de Educação Fundamental.

2004a Resolução n. 2, de 8 de março de 2004. Aprova as Diretrizes Curriculares Nacionais do Curso de Graduação em Música e dá outras providências. Brasília: CNE/CES.

2004b Resolução n. 3, de 8 de março de 2004. Aprova as Diretrizes Curriculares Nacionais do Curso de Graduação em Dança e dá outras providências. Brasília: CNE/CES.

2004c Resolução n. 4, de 8 de março de 2004. Aprova as Diretrizes Curriculares Nacionais do Curso de Graduação em Teatro e dá outras providências. Brasilia: CNE/CES.

2008 Lei n. 11.769, de 18 de agosto de 2008. Brasília: Diário Oficial da União, ano CXLV, n. 159, de 19/08/2008, Seção 1, página 1.

2009 Resolução n. 1, de 16 de janeiro de 2009. Aprova as Diretrizes Curriculares Nacionais do Curso de Graduação em Artes Visuais e dá outras providências. Brasilia: CNE/CES. 